Int. J. Electrochem. Sci., 15 (2020) 3793 - 3806

\title{
The Effect of Tungsten Inert Gas Welding on the Pitting Corrosion Behavior of 304 Stainless Steel
}

\author{
Qiushi Li ${ }^{1,2,3,4}$, Jihui Wang ${ }^{2, *}$, Ke Wang ${ }^{2, *}$, Huan Wang ${ }^{2}$, Wenbin $H u^{2}$ \\ ${ }^{1}$ Tianjin Port Engineering Institute Co., Ltd., CCCC First Harbor Engineering Co., Ltd., Tianjin \\ 300222, P R China \\ 2 Tianjin Key Laboratory of Composite and Functional Materials, School of Materials Science and \\ Engineering, Tianjin University, Tianjin 300072, P R China \\ 3 Tianjin Key Laboratory of Underwater Tunnel Construction and Operation \& Maintenance \\ Technology, Tianjin 300222, P R China \\ ${ }^{4}$ CCCC First Harbor Engineering Co., Ltd., Tianjin 300461, P R China \\ *E-mail: jhwang@tju.edu.cn, kewang@tju.edu.cn
}

doi: $10.20964 / 2020.05 .40$

Received: 12 December 2019 / Accepted: 24 February 2020 / Published: 10 April 2020

The effect of Tungsten Inert Gas Welding on the pitting corrosion behavior of 304 stainless steel (SS) in the $0.5 \mathrm{~mol} / \mathrm{L} \mathrm{NaCl}$ solution was investigated by potentiodynamic polarization, dynamic electrochemical impedance spectroscopy and electrochemical noise. The results indicated that the pitting resistance of the welded 304SS is weaker than that of the base 304SS. For the welded 304SS, metastable pit was observed with a slow generation and healing. For the base 304SS, metastable pit was also observed, but with a fast initiation and death. The related pitting mechanisms of both samples were also discussed.

Keywords: Stainless steel, Welding, Dynamic electrochemical impedance spectroscopy, Electrochemical noise

\section{FULL TEXT}

(C) 2020 The Authors. Published by ESG (www.electrochemsci.org). This article is an open access article distributed under the terms and conditions of the Creative Commons Attribution license (http://creativecommons.org/licenses/by/4.0/). 